\title{
Sirtuin 1 Targeting Reverses Innate and Adaptive Immune Tolerance in Septic Mice
}

\author{
Ayana N. Martin, ${ }^{1}$ Martha Alexander-Miller, ${ }^{2}$ Barbara K. Yoza $\left(\mathbb{D},{ }^{3}\right.$ Vidula Vachharajani $\mathbb{D},{ }^{1,4}$ \\ and Charles E. McCall $\mathbb{1}^{5}$ \\ ${ }^{1}$ Department of Molecular Medicine \& Translational Science, Wake Forest School of Medicine, Winston-Salem, NC, USA \\ ${ }^{2}$ Department of Microbiology \& Immunology, Wake Forest School of Medicine, Winston-Salem, NC, USA \\ ${ }^{3}$ Department of Surgery, Wake Forest School of Medicine, Winston-Salem, NC, USA \\ ${ }^{4}$ Department of Anesthesiology, Wake Forest School of Medicine, Winston-Salem, NC, USA \\ ${ }^{5}$ Department of Internal Medicine, Wake Forest School of Medicine, Winston-Salem, NC, USA
}

Correspondence should be addressed to Charles E. McCall; chmccall@wakehealth.edu

Received 28 March 2018; Accepted 29 May 2018; Published 4 July 2018

Academic Editor: Anil Shanker

Copyright (c) 2018 Ayana N. Martin et al. This is an open access article distributed under the Creative Commons Attribution License, which permits unrestricted use, distribution, and reproduction in any medium, provided the original work is properly cited.

\begin{abstract}
Resistance and tolerance to infection are two universal fitness and survival strategies used by inflammation and immunity in organisms and cells to guard homeostasis. During sepsis, however, both strategies fail, and animal and human victims often die from combined innate and adaptive immune suppression with persistent bacterial and viral infections. NAD ${ }^{+}$-sensing nuclear sirtuin1 (SIRT1) epigenetically guards immune and metabolic homeostasis during sepsis. Pharmacologically inhibiting SIRT1 deacetylase activity in septic mice reverses monocyte immune tolerance, clears infection, rebalances glycolysis and glucose oxidation, resolves organ dysfunction, and prevents most septic deaths. Whether SIRT1 inhibition during sepsis treatment concomitantly reverses innate and $\mathrm{T}$ cell antigen-specific immune tolerance is unknown. Here, we show that treating septic mice with a SIRT1 selective inhibitor concordantly reverses immune tolerance splenic dendritic and antigen-specific tolerance of splenic CD4+ and CD8+ T cells. SIRT1 inhibition also increases the ratio of IL12 p40+ and TNF $\alpha$ proinflammatory/immune to IL10 and TGF $\beta$ anti-inflammatory/immune cytokines and decreases the ratio of CD4+ $\mathrm{T}_{\text {Reg }}$ repressor to CD4+ activator T cells. These findings support the unifying concept that nuclear $\mathrm{NAD}^{+}$sensor SIRT1 broadly coordinates innate and adaptive immune reprogramming during sepsis and is a druggable immunometabolic enhancement target.
\end{abstract}

\section{Introduction}

A universal concept in evolutionary biology is that the inflammatory stress response protects homeostasis by resistance or tolerance $[1,2]$. In sepsis extreme systemic inflammation [3], the high energy-demanding switch that promotes anabolic growth and differentiation of biosynthetic processes needed to resist invading microbes rapidly switches to tolerance, a very low energy state simulating suspended animation or severe starvation that invokes profound immune suppression of both innate and antigen-specific T cells; many sepsis victims perish from persistent infections associated with immune failure. Understanding how sepsis survivors "break" immune tolerance and its attendant profound innate and adaptive immune suppression to resolve the acute inflammatory response to infection may inform new ways to treat sepsis.

We pioneered the concept that $\mathrm{NAD}^{+}$redox and intermediary metabolism sensors sirtuin1 (SIRT1) and sirtuin6 (SIRT6) epigenetically reprogram the universal attributes of resistance to tolerance in monocytes by shifting glycolysis and glucose oxidation high energy use to the low energy state lipolysis by generating silent heterochromatin at selective sets of immune and metabolism fueling gene sets $(\mathrm{TNF} \alpha)[4,5]$ and maintaining open euchromatin at reciprocally functioning gene sets [6-8]. We further showed that chronic $\mathrm{NAD}^{+}$ generation persistently promotes SIRT1 activation in monocytes to maintain immune tolerance in monocytes in mice 
and human sepsis [5]. Strikingly, inhibiting SIRT1 in septic mice reverses innate immune tolerance in monocytes and tolerance of microvascular leukocyte/endothelial adherence interactions and promotes survival [9]. Moreover, interferon gamma $(\operatorname{IFN} \gamma)$ administered in vivo or ex vivo to mouse or human monocytes obtained during sepsis reversed the phenotype of glycolysis deactivation and innate immune tolerance of monocytes [10].

Studies in mice and humans indicate that adaptive immunity $\mathrm{T}$ cells also become tolerant during sepsis, variously called "anergy" in CD4+ Th1 effector cells $[11,12]$ and "exhaustion" in CD8+ cytotoxic T cells $[13,14]$. Mounting data support that metabolic substrate selection drives inflammation in innate and adaptive immune cell effector and repressor phenotypes [15-18]. Like innate immune monocytes, tolerant adaptive immune $\mathrm{T}$ cells are unable to mount a glycolysis-dependent response needed to anabolically fuel immune resistance responses following antigenreceptor stimulation, suggesting a common checkpoint for immune reprogramming [13]. Clinically, the emergence of tolerant innate and adaptive immune cells during sepsis also parallels elevations in $\mathrm{CD} 4+\mathrm{T}$ regulatory repressor $\left(\mathrm{T}_{\mathrm{Reg}}\right)$ [19] cells, as well as the increased production of antiinflammatory and antiglycolytic interleukin 10 (IL10) [20] and immune repressor transforming growth factor beta $(\mathrm{TGF} \beta)[21]$. Increases in the ratio of immune repressor cell $\mathrm{T}_{\text {Reg }}$ and exhausted/anergic/tolerance phenotypes during sepsis mark the clinical state of chronic bacterial and recrudescent viral infections $[22,23]$. However, whether innate and adaptive immunity and organ-specific tolerance states are under a unified control axis during sepsis is unknown [24].

SIRT1 is a nuclear $\mathrm{NAD}^{+}$redox and metabolism sensor that acts epigenetically in most cells as a homeostasis guardian that coordinates immune and inflammation polarity in [5, 25-29]. SIRT1 reprogramming of immune polarity occurs in vitro in monocytes [4, 5, 30-32], macrophages [33, 34], and in CD4 and CD8 T cells and tolerogenic dendritic cells [35-40]. SIRT1 plays a key role in inducing CD11c tolerogenic dendritic cells in vivo in mice and informs CD4+ $\mathrm{T}$ effector Th1 and repressor CD4+ repressor cell and their respective link to cytokine production during endotoxin tolerance [36]. An in vivo link between innate and adaptive immune resistance and tolerance reprogramming during sepsis has never been reported to our knowledge. If this coupling occurs during sepsis, it would suggest that SIRT1 targeting of the global immune dysregulated state of innate and adaptive immune cells might inform a unified sepsis treatment approach for immune enhancement treatment of human sepsis.

Here, we report that therapeutic targeting of immune tolerant $\mathrm{C} 57 \mathrm{BL} / 6$ septic mice $24 \mathrm{~h}$ after cecal ligation and puncture (CLP) with $10 \mathrm{mg} / \mathrm{kg}$ of EX-527, a SIRT1selective inhibitory dose substantially increases survival [9], reverses innate and adaptive immune tolerance. EX-527 decreased the CD4+Foxp3+CTLA4+ $\mathrm{T}_{\text {Reg }}$ cell population able to express IL10 and TGF $\beta$ repressor cytokines and increased the proportion of CD4+ T cells able to express interferon $\gamma$. EX-527 also reversed antigen-receptor-dependent tolerance among total splenocyte adaptive immunity populations. Concomitant with the switch away from adaptive immune cell tolerance toward the effector resistance, phenotype was reversal of splenic tolerogenic CD11c+ dendritic cells, as evidenced by increased interleukin 12 p40 (IL12 p40) and TNF $\alpha$ expression following nonspecific cell stimulation. Remarkably, as we had found for innate immune monocytes [9], SIRT1 inhibition significantly switched the adaptive immunity away from tolerance toward resistance within $6 \mathrm{~h}$ after a single dose of EX-527. This study is consistent with the unifying concept that a nuclear immunometabolic checkpoint controlled at least in part by SIRT1 directs innate and adaptive immune reprogramming during sepsis and informs molecular-based immune axis targeting.

\section{Materials and Methods}

2.1. Mice. This study was approved by the Institutional Animal Care and Use Committee of the Wake Forest School of Medicine according to NIH guidelines. 6-8week-old male WT mice $(\mathrm{C} 57 \mathrm{Bl} / 6)$ from Jackson Laboratory (Bar Harbor, ME, USA) were randomized into Sham, CLP, or CLP + EX-527 groups, with 5 mice/experimental group. The experimental protocol for this study was used precisely as previously reported for EX-527 to test its effect on innate immunity, vascular and microvascular function, and survival [5]. The present mice were used to compare previous studies of innate immunity with this focused study of innate and adaptive immunity in concert.

2.2. CLP Sepsis Model. Cecal ligation and puncture (CLP) has been standardized in our sepsis model in C57Bl6 mice [5]. Briefly, the cecum was externalized from the peritoneal cavity, ligated, and perforated twice with a 22-gauge needle, which induces a $\sim 60 \% 14 \mathrm{~d}$ mortality rate. For the sham surgery, the cecum was externalized and returned to the cavity. Fluid resuscitation ( $1 \mathrm{~mL}$ normal saline) was administered s.c. after surgery. No antibiotics were given.

2.3. SIRT1 Targeting Treatment Design. Treatment protocol was followed exactly as reported in the SIRT1 study of monocytes and sepsis outcome [5]. Briefly, $10 \mathrm{mg} / \mathrm{kg}(4 \mathrm{~mL} / \mathrm{kg})$ of EX-527 (made in DMSO and delivered in normal saline) was injected i.p. $24 \mathrm{~h}$ postsurgery in CLP animals; untreated CLP and Sham control animals received equivalent volume of DMSO $(4 \mathrm{~mL} / \mathrm{kg})$ in normal saline at $24 \mathrm{~h}$ postsurgery of about $1 \mu \mathrm{M}$, as a small molecule broadly distributes in tissue and has no known off target effects. EX-527 (obtained from Sigma Chemicals, St. Louis, MO) is a potent and selective inhibitor of SIRT1 activity [41]. It binds in the catalytic cleft of SIRT1, displacing the $\mathrm{NAD}^{+}$and forcing the cofactor into an extended conformation, thus sterically preventing substrate binding in the catalytic domain. It is 200-500fold more selective for SIRT1 than for SIRT2, SIRT3, or SIRT6, has a half-life of $2 \mathrm{~h}$, and is active in $<100 \mathrm{nM}$ concentrations [42].

In selecting the time for EX-527 i.p. administration for this study, we were guided by our previous report that microvascular inflammation tolerance in vivo is fully established by 
$24 \mathrm{~h}$ after CLP. We further reported that $6 \mathrm{~h}$ posttreatment time point $(30 \mathrm{~h}$ after CLP) detects EX-527-dependent tolerance reversal in monocyte cytokine production and in microvascular leukocyte-endothelial adhesion [5]. Accordingly, this study focused on the $24 \mathrm{~h}$ sepsis post-CLP as treatment time and the previously used $6 \mathrm{~h}$ posttreatment time point for analyses of innate and adaptive immunity, using isolated splenocytes. Markedly increased survival after EX-527 occurs under these same conditions.

2.4. Splenocyte Isolation and Flow Cytometry. Splenocytes were harvested as reported [9], using $500 \mu \mathrm{L}$ Collagenase D solution at a concentration of $1 \mathrm{mg} / \mathrm{mL}$, which was scissor cut and passed through a $70 \mu \mathrm{m}$ cell suspensions of $1 \times 10^{7}$ cells $/ \mathrm{mL}$ in Flow Cytometry Staining Buffer (PBS with 5\% FBS). Cells were run on the BD FACSCanto II and analyzed using FlowJo v10 for assessing scatter, frequency, cell number, and mean fluorescent intensity per cell. For $6 \mathrm{~h}$ and for $12 \mathrm{~h}$ postsepsis treatment analyses, sham versus CLP animals were compared. For $24 \mathrm{~h}$ post-CLP treatment, sham versus CLP versus CLP + EX-527 animals were compared after $6 \mathrm{~h}$ (30 h post-CLP).

2.5. Antibodies Used in Flow Cytometry. Cell surface antigens were stained first. The dendritic cell antibody panel quantified the following: CD11c-APC-eFluor780, CD80-PE-Cy7, CD86-FITC, and CD40-eFluor450 (all $\mathrm{mAbs}$ are from eBioscience now Thermo Fisher, Waltham, MA). The $\mathrm{CD} 4+\mathrm{T}_{\mathrm{Reg}}$ cell panel included the following: CD3e-PE, CD4-PE-Cy7, and CD25-PerCP-Cy5.5s (all mAbs are from eBioscience). For $\mathrm{T}_{\mathrm{Reg}}$ intracellular staining, cells were fixed and permeabilized with the one step eBioscience FixPerm Foxp3 Buffer Staining Kit (eBioscience). The panel included Foxp3-eFluor450 and CTLA4-APC (mAbs are from eBioscience). Intracellular staining was also used to detect TGF $\beta$-PE, IL12 p40-PE, IL10-APC, and IFN $\gamma$-APC production (mAbs are from eBioscience) after ex vivo nonspecific antigen stimulation with a Leukocyte Activation Cocktail with GolgiPlug (BD Biosciences) for flow cytometry. Mouse INF $\gamma$ Single-Color ELISPOT to determine antigenspecific response of $\mathrm{T}$ cells was from Cellular Technology Limited (CTL), Cleveland, OH. For attempting to assess SIRT1 expression by flow cytometry, we used antibodies from Santa Cruz and Abcam.

2.6. Data Analysis. All data were analyzed using GraphPad Prism 6.0 (GraphPad Software, La Jolla, CA, USA). Our studies are powered at 5-7 animals per group per 2 experiments, but the numbers are increased as needed based on variability. For analyses between two population means, we used unpaired, two-tailed Student's $t$-test analyses. Groups of more than three comparisons were analyzed using oneway ANOVA, followed by Tukey's post hoc $t$-test. Significance is indicated with an asterisk indicating ${ }^{*} p<0.05$. Error bars represent \pm SEM. In the figures, all values are depicted with the number of animals in the experimental conditions along with single asterisks indicating our significance threshold of $p<0.05$ to make it easier to follow. The precise value can be found in the text. Trends not reaching the $p<0.05$ can be appreciated by scatter box depictions.

\section{Results}

3.1. Total CD4+ T Cells, but Not Total CD8+ T Cells, Decrease in the Spleen during Early Sepsis. $\mathrm{T}_{\mathrm{Reg}}$ cells can be found in both $\mathrm{CD} 4+$ and $\mathrm{CD} 8+\mathrm{T}$ cell populations [43]; therefore, we first determined whether the CD4+ and/or CD8+ T cell populations were impacted by early sepsis. Splenocytes isolated from the spleens of sham and CLP mice were stained with anti-CD4 and anti-CD8 antibodies. Total splenocyte counts decreased in the CLP mice, compared to the sham control (Figure 1(a); sham $=6.18 \times 10^{7} \pm 6.35 \times 10^{6}$ cells, $\mathrm{CLP}=3.75 \times 10^{7} \pm 5.84 \times 10^{6}$ cells; $\left.p=0.0086\right)$. At $30 \mathrm{~h}$ postCLP, the frequency of CD4+ T cells in CLP mice significantly decreased as compared to sham (Figure 1(b); sham $=17.94 \pm$ $1.98 \%, C L P=13.57 \pm 0.59 \% ; p=0.0025)$. This difference also translated to the absolute cell count (Figure 1(c); ham $=5.35 \times 10^{6} \pm 5.40 \times 10^{5}$ cells, CLP $=3.35 \times 10^{6} \pm 6.77 \times 10^{5}$ cells; $p=0.0285$ ). In contrast to the sepsis-induced changes in $\mathrm{CD} 4+\mathrm{T}$ cells at $30 \mathrm{~h}$, the frequency and absolute cell numbers of CD8+ T cells were similar between sham and CLP (Figures 1(d) and 1(e); $p=0.79$ and $p=0.99$, resp.). SIRT1 inhibition with EX-527 had no effect on the diminished CD4+ T cell population in frequency or absolute cell count compared to CLP treatment (Figures 1(b) and 1(c); $p=0.55$ and $p=0.98$, resp.). CD8+ T cells also showed no changes in response to SIRT1 inhibition in frequency or absolute cell count (Figures 1(d) and 1(e); $p=0.68$ and $p=0.69$, resp.). Taken together, these data suggest that sepsis differentially affects CD4+ versus CD8+ T cells during the early immunosuppression. These data are similar to other reports on sepsis-induced apoptosis dominance in CD4+ T cells and dendritic cells [44].

3.2. SIRT1 Inhibition Reverses CD4+ T Cell Cytokine Polarity and Tolerance of Total T Cell IFN $\gamma$ Expression after AntigenReceptor Stimulation. To build upon our unifying concept of SIRT1 as a master homeostat of immune system function, we tested cytokine secretion in the spleen as ex vivo biomarkers of a functional switch in immune function. To do this, splenocytes were collected at $30 \mathrm{~h}$ from sham, CLP, and CLP + EX-527 mice and treated with phorbol myristate acetate (PMA) + ionomycin cocktail to induce cytokine production, while preventing release with GolgiPlug in order to detect by flow cytometry. In Figure 2, we show a shift away from proimmune CD4+ T cell responses toward antiinflammatory responses during sepsis that support a suppressive $\mathrm{CD} 4+$-adaptive immune response. The frequency of $\mathrm{TNF} \alpha$, a major proinflammatory and immune activator, is decreased in septic mice at $30 \mathrm{~h}$ compared to sham (Figure 2(a); sham $=27.44 \pm 0.86 \%, \quad$ CLP $=15.84 \pm 0.94 \%$; $\left.p=1.73 \times 10^{-5}\right)$. Similarly, the frequency of proimmune mediator IFN $\gamma$ also decreased in septic mice at $30 \mathrm{~h} \mathrm{com-}$ pared to sham (Figure 2(b); sham $=0.78 \pm 0.02 \%$, CLP $=$ $0.5 \pm 0.03 \% ; p=0.0003$ ). Concomitant with the decrease in $\mathrm{CD} 4+\mathrm{T}$ cell-derived proinflammatory cytokine production, the frequency of key repressor IL10 was significantly 


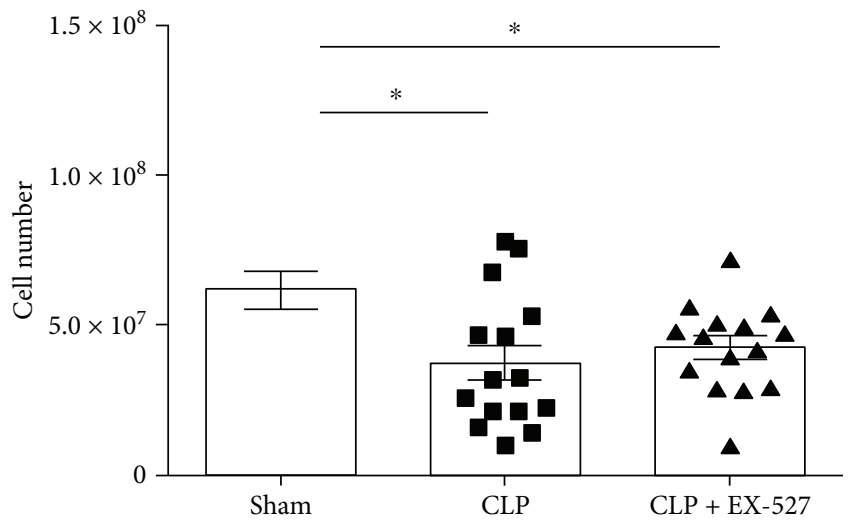

(a)

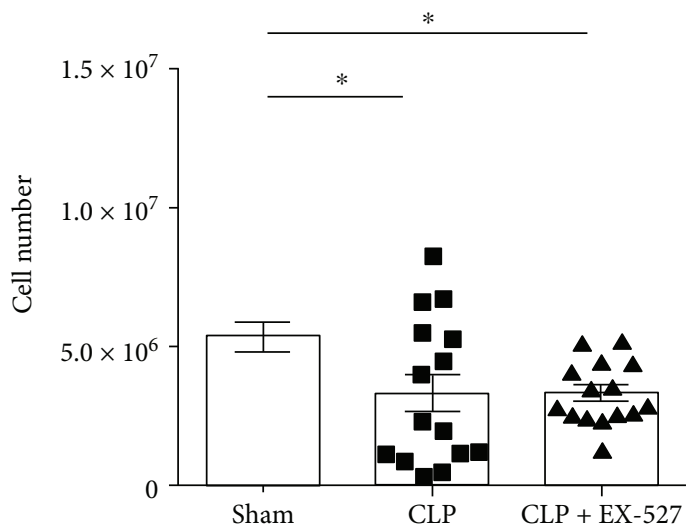

(c)

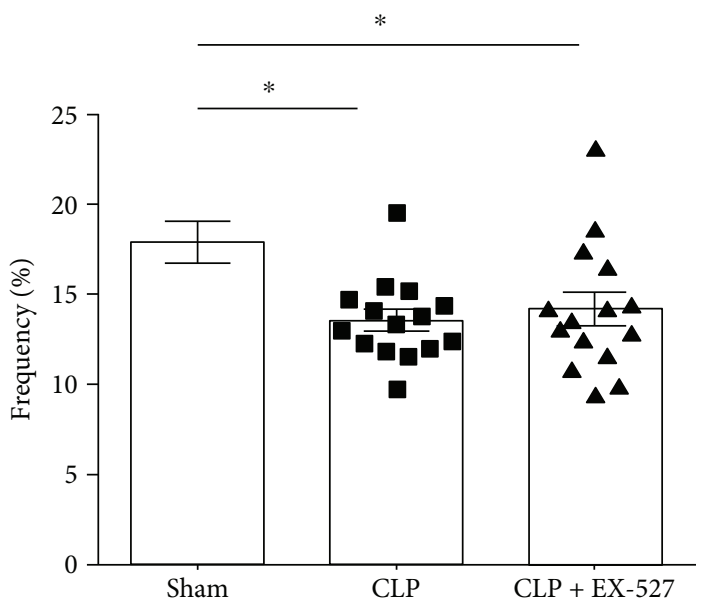

(b)

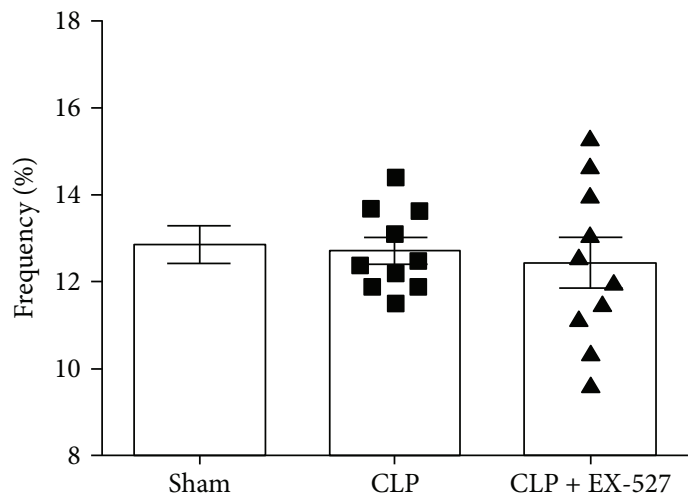

(d)

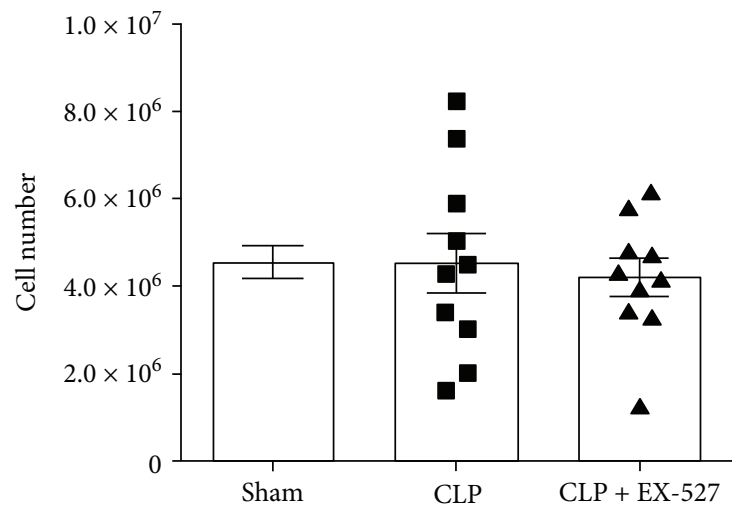

(e)

FIgURE 1: SIRT1 inhibition has no effect on frequency and number changes in total splenocyte and CD4+ T cells during sepsis-induced immunosuppression. All data presented as sham versus CLP versus CLP + EX-527. (a) Cumulative results of total splenocytes presented as total cell number. (b, c) Cumulative results from surface CD4 presented as (b) frequency of total splenocytes (\%) and (c) absolute cell count. (d, e) Cumulative results from surface CD8 presented as (d) frequency of total splenocytes (\%) and (e) absolute cell count. Data are representative of three independent analyses with a total of 5 mice in each group. Data are expressed as mean \pm SEM. $n=15$ mice/group. $* p<0.05$.

increased in septic mice at $30 \mathrm{~h}$ compared to sham (Figure 2(d); sham $=2.14 \pm 0.12 \%, C L P=2.92 \pm 0.1 \% ; p=$ $0.0011)$. While TGF $\beta$ was not significantly increased during sepsis (Figure 2(c)), EX-527 significantly decreased TGF $\beta$ (Figure 2(c)) and IL10 (Figure 2(d)) frequency compared to nontreated CLP mice ( $p=0.029$ and $p=0.035$, resp.). Importantly and concurrent with the shift away from CD4+ anti-inflammatory cytokine production, SIRT1 inhibition increases in the frequency of IFN $\gamma$ cytokine production in CD4+ $\mathrm{T}$ cells, compared with CLP (Figure 2(b); 
$\mathrm{CD} 4+\mathrm{TNF} \alpha+$

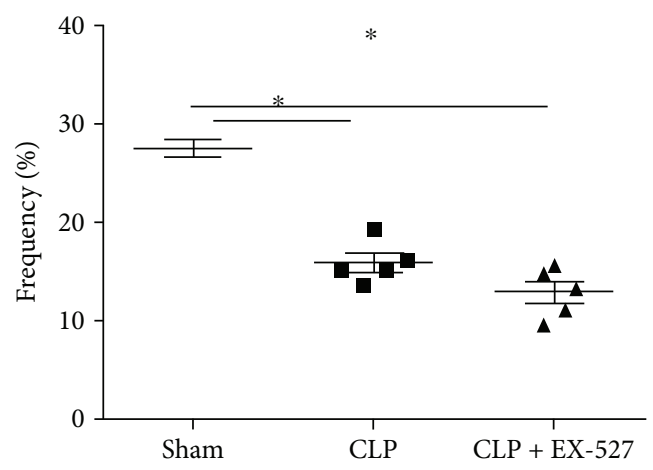

(a)

CD4+TGF $\beta+$

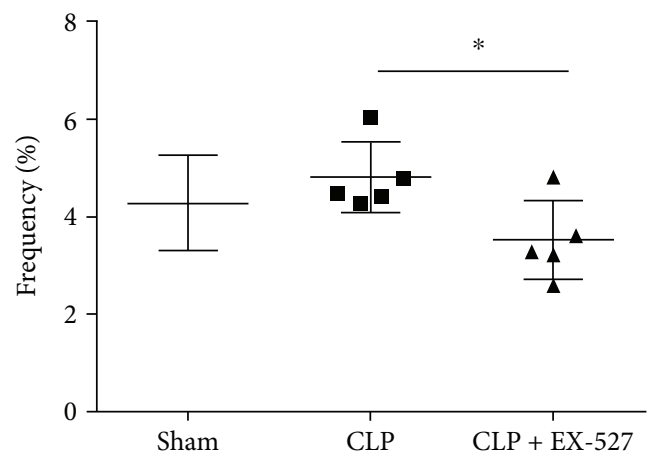

(c)

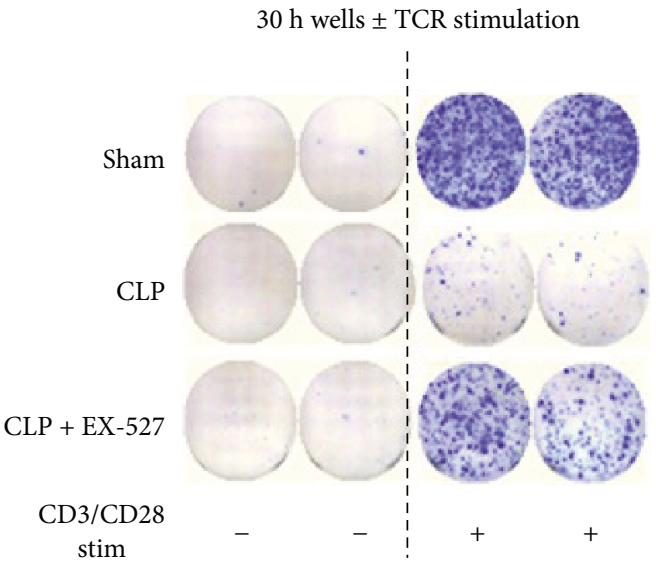

(e)
$\mathrm{CD} 4+\mathrm{IFN} \gamma+$

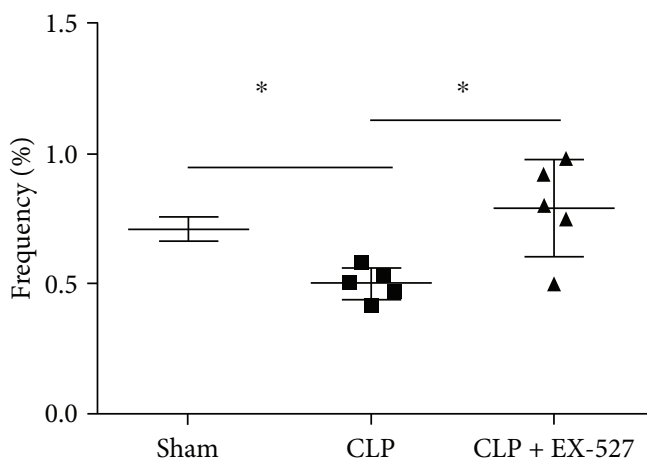

(b)

CD4+IL10+

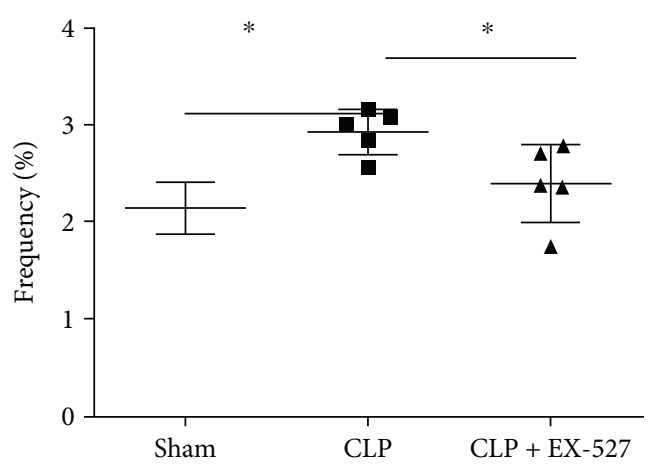

(d)

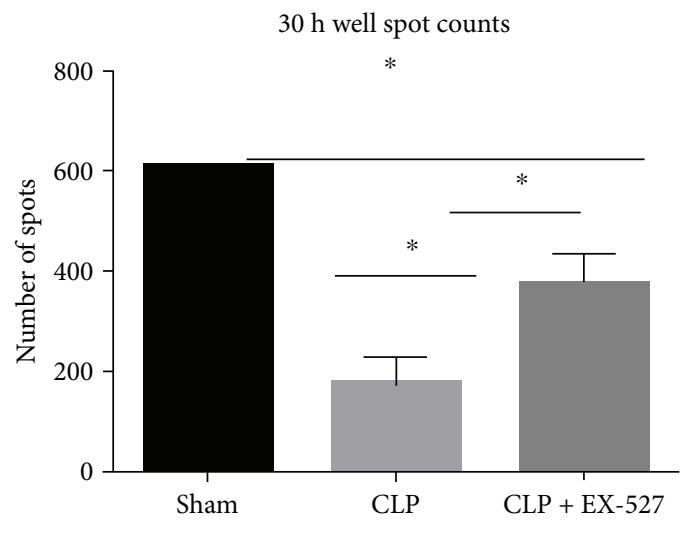

(f)

FIgURE 2: CD4+ $\mathrm{T}$ cell-associated cytokines are reprogrammed in a SIRT1-dependent manner. Cumulative scatterplot data of proinflammatory (a) CD4+TNF $\alpha+\mathrm{T}$ cells and (b) CD4+IFN $\gamma+\mathrm{T}$ cells presented as frequency of CD4+ T cells in sham versus CLP versus CLP + EX-527. Cumulative scatterplot data of anti-inflammatory (c) CD4+TGF $\beta+\mathrm{T}$ cells and (d) CD4+IL10+ T cells presented as frequency of CD4+ $\mathrm{T}$ cells in sham versus CLP versus CLP + EX-527. (e) Representative ELISPOT data of IFN $\gamma$ producing T cells \pm restimulation from sham versus CLP versus CLP + EX-527 mice. (f) Cumulative results presented as spots counted per well from sham versus CLP versus CLP + EX-527, based on cells seeded at $3 \times 10^{5}$ cells/well. Data are expressed as mean \pm SEM. (a-d) $n=5$ mice/group; (e, f) $n=3$ mice/group. ${ }^{*} p<0.05$.

$\mathrm{CLP}=0.5 \pm 0.03 \%, \mathrm{CLP}+\mathrm{EX}-527=0.79 \pm 0.08 \% ; p=0.011)$. These findings support the reversal of CD4+ Th1 cell anergy during SIRT1 inhibition.

To assess the function of the antigen-receptor following SIRT1 treatment during sepsis immune tolerance, we measured IFN $\gamma$ production from total $\mathrm{T}$ cell antigen-receptor- stimulated T cells (including CD4+ and CD8+). Splenocytes isolated from sham, CLP, and CLP + EX-527 mice were restimulated overnight with $\alpha$-CD3/ $\alpha$-CD28 at $500 \mathrm{ng} / \mathrm{mL}$ and $5 \mu \mathrm{g} / \mathrm{mL}$, respectively. IFN $\gamma$ production was quantified using ELISPOT by counting the number of spots with immunoprecipitated detection antibody (Figure 2(e)). Figure 2(f) 
demonstrates that CD3/CD28 antigen-receptor stimulation is unable to increase IFN $\gamma$ production during sepsis ( ham $=610 \pm 2.5$ spots per $3 \times 10^{5}$ cells, CLP $=173 \pm 56.4$ spots per $3 \times 10^{5}$ cells; $p=0.0011$ ), supporting antigenspecific receptor "tolerance" during sepsis. This in vivo assessment aligns with in vitro studies showing SIRT1 as a key promoter of antigen-dependent tolerance of CD4+ and CD8+ T cells [30]; SIRT1 is also a key contributor to tolerance monocytes in vitro and in mouse sepsis $[4,5,7]$. In this study, EX-527 selective SIRT1 inhibitor increased IFN $\gamma$ secretion after TCR stimulation compared to CLP (Figure 2(f); CLP $=173 \pm 56.4$ spots per $3 \times 10^{5}$ cells; CLP + EX-527 $=378 \pm 57.2$ spots per $3 \times 10^{5}$ cells; $\left.p=0.034\right)$. Taken together with published data and our findings, these findings support that SIRT1 reverses CD4+ tolerance and CD8+ T cell exhaustion and broadly promotes $\mathrm{T}$ cell homeostasis. We were unable to detect SIRT1 in any spleen cell by flow cytometry, leaving the possibility that cell autonomous or nonautonomous SIRT1-dependent cross-talk reprograms the CD4+ and CD8+ homeostat.

3.3. SIRT1 Inhibition Decreases CD4+Foxp3 $+T_{\text {Reg }}$ Repressor Frequency. SIRT1 may also promote the repressor phenotype of CD4+Fox $3 \mathrm{p}+\mathrm{T}_{\text {Reg }}$ cells, which are known to increase during sepsis $[19,45,46]$. We next tested whether the CD4+ $\mathrm{T}_{\text {Reg }}$ cells increase in early sepsis of our model and might contribute along with $\mathrm{CD} 4+\mathrm{T}$ cell anergy to immune suppression. We first determined the CD4+ subpopulation of $\mathrm{T}_{\text {Reg }}$ cells exclusively, as there were no changes in the CD8+ T cell population at the $30 \mathrm{~h}$ postsepsis time point of our study on innate and adaptive immunity coordination. CD4 $+\mathrm{T}_{\text {Reg }}$ cells were defined by Foxp3 transcription factor, the master regulator of $\mathrm{T}_{\text {Reg }}$ cell lineage [47]. CD4+Foxp3 $+\mathrm{T}_{\text {Reg }}$ cells from CLP mice significantly increased to $17.26 \pm 0.41 \%$ from the $12.56 \pm 0.34 \%$ CD4+Foxp3 $+T_{\text {Reg }}$ cells from sham mice (Figure 3(a), $\left.p=1.46 \times 10^{-9}\right)$. The absolute cell count was not statistically significant (Figure $3(\mathrm{~b})$; sham $=8.97 \times 10^{5} \pm 7.04 \times 10^{4}$ cells, $\mathrm{CLP}=1.07 \times 10^{6} \pm 8.23 \times 10^{4}$ cells; $\left.p=0.11\right)$. These data suggest reciprocal changes CD4+ Th1 and $\mathrm{T}_{\mathrm{Reg}}$ repressor cells occur in the spleen in septic mice and are directly or indirectly coordinated by SIRT1. They further support SIRT1 as a molecular target for deprogramming tolerance and immune repression during sepsis.

We previously demonstrated disrupting SIRT1 $24 \mathrm{~h}$ after sepsis promotes immunometabolic competence in monocytes within $6 \mathrm{~h}$ and markedly improves 7 day survival in septic mice $[5,9,32]$. Surprisingly, SIRT1 inhibition by a single i.p. dose of EX-527 also shifts adaptive immunity within 6 h of treatment (Figure 3(c)), as supported by the significantly reduced CD4+Fox $3 \mathrm{~T}_{\text {Reg }}$ CTLA+ frequency following EX-527 treatment of septic mice $(C L P=11.37 \pm 0.79 \%$, $\mathrm{CLP}+\mathrm{EX}-527=8.76 \pm 0.63 ; p=0.0156)$.

To better characterize the biological impact of the enhanced $\mathrm{T}_{\text {Reg }}$ cell proportions during sepsis-induced polarization, CTLA4 expression was measured as a marker for the immune repressor property of $\mathrm{T}_{\text {Reg }}$ cells [48]. Figure 3(c) shows that CD4+Foxp3+CTLA4+ $\mathrm{T}_{\text {Reg }}$ cells increase in frequency during sepsis as compared to sham
$($ sham $=5.26 \pm 0.81 \%, \quad$ CLP $=9.31 \pm 0.88 \% ; p=0.002)$ and that SIRT1 inhibition significantly reduces CD4+Foxp3+ CTLA4+ $\mathrm{T}_{\text {Reg }}$ cell subpopulations (Figure 3(c)). The absolute cell counts of all the measured $\mathrm{T}_{\text {Reg }}$ subpopulations also decreased, but without statistical significance (Figure 3(d)).

Taken together, the changes in CD4+Foxp3+ and CD4+Foxp3+CTLA4+ $\mathrm{T}_{\text {Reg }}$ cells suggest that SIRT1 inhibition selectively reprograms the balance of $\mathrm{CD} 4+\mathrm{T}$ cells to favor improved CD4+ T cell effector immune functions. This switch occurs without detectable changes in the total despite splenocyte population after a single dose of EX-527. Figure 3(e) summarizes CD4 $+\mathrm{T}_{\text {Reg }}$ cell population and immune functional changes. The representative figure shown highlights the ratio changes in population size of CD4+ T cells and $\mathrm{CD} 4+\mathrm{T}_{\text {Reg }}$ subpopulation (note: markers are not representative of surface versus intracellular location). During sepsis, the total CD4+ $\mathrm{T}$ cell population significantly decreases, while the CD4+ $\mathrm{T}_{\text {Reg }}$ cell subpopulation significantly increases, thus shifting the balance in favor of immune suppression. SIRT1 inhibition reduces the CD4+ $\mathrm{T}_{\text {Reg }}$ cell subpopulation, without increasing the CD4+ T cell population. This subpopulation reprogramming may restore adaptive immune homeostasis.

3.4. SIRT1 Inhibition Shifts Reprogramming of DC CD80 and CD86 Expression. Recently published data [36] clearly showed that SIRT1 plays an obligated role in supporting the function of tolerogenic dendritic cells in C57BL6 mice and their control of the CD4+ $\mathrm{T}$ effector and $\mathrm{T}$ repressor cell polarity. That study used genetic and pharmacologic analysis with EX-527; however, it did not investigate sepsis, which does not lend itself to genetic approaches to follow resistance and tolerance reprogramming kinetically. Mature DCs activate T cells through costimulatory molecules CD80 and CD86 and then are reprogrammed during sepsis to a tolerogenic state $[49,50]$. CD80 may promote and CD86 may inhibit $\mathrm{T}_{\text {Reg }}$ cell proliferation [51-53].

To identify splenic DCs and test their role in sepsis reprogramming of $\mathrm{CD} 4+\mathrm{T}$ cells, isolated splenocytes from sham, CLP, and CLP + EX-527 mice were stained with antiCD11c, anti-CD80, and anti-CD86 antibodies. Because CD11c+ DCs are innate immune cells that communicate with adaptive immune cells, CD11c+ DCs were assessed at $6 \mathrm{~h}, 12 \mathrm{~h}$, and $30 \mathrm{~h}$, including a $24 \mathrm{~h}$ CLP with and without EX-527 treatment to determine kinetics. Consistent with splenocyte apoptosis [54], CD11c+ DCs decreased at $30 \mathrm{~h}$ post-CLP (Figure 4(a); sham $=10.3 \pm 1.29 \%, C L P=6.33 \pm$ $1.31 \% ; p=0.0395)$. The differential changes in CD80 and CD86 expression on CD11c+ DCs during the early and late phases of our sepsis model suggest that CD80+ and CD86+ are differentially modulated due to sepsis, so we determined whether SIRT1 inhibition balances this pattern. SIRT1 inhibition by EX-527 did not alter CD11c+ percentages in the spleen (Figure 4(a)), but the frequency of CD11c+CD80+ DCs was reduced compared to CLP (Figure 4(b)). In contrast, SIRT1 inhibition had no significant effect on the frequency or fold change of CD11c+CD86+ dendritic cells compared to CLP (Figure 4(c); $p=0.37$ ). These data suggest that SIRT1 inhibition during sepsis may promote dendritic 
CD4+Foxp3+

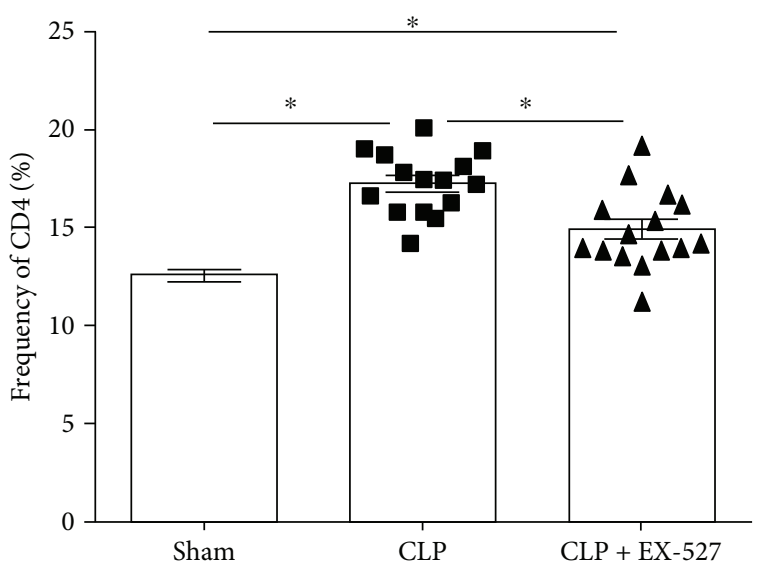

(a)

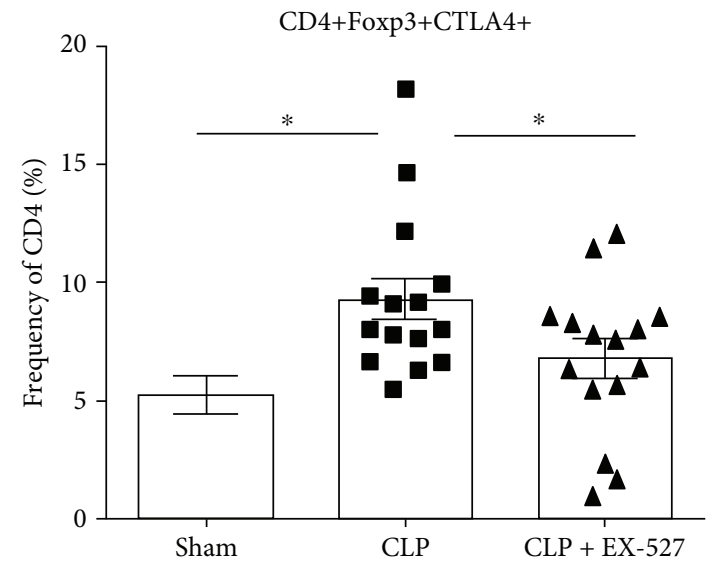

(c)

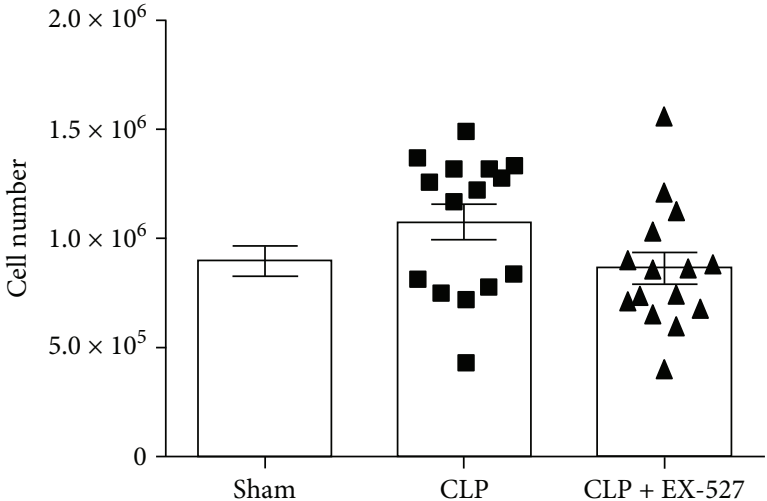

(b)

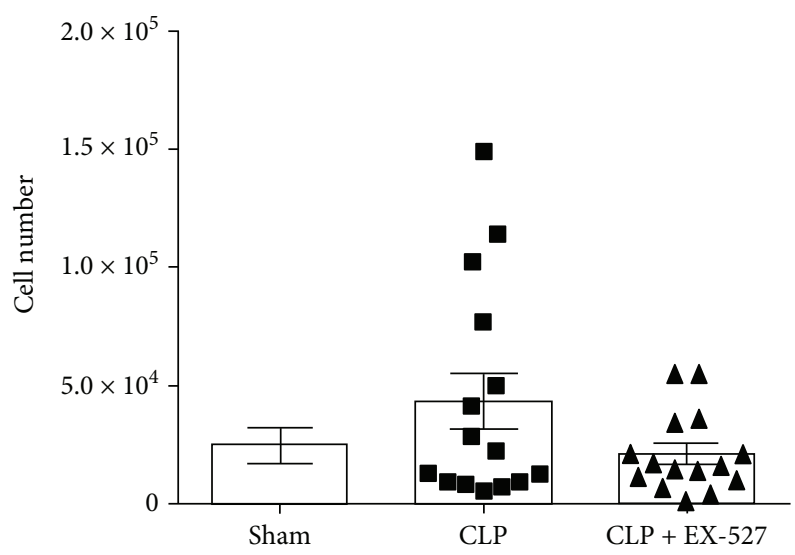

(d)

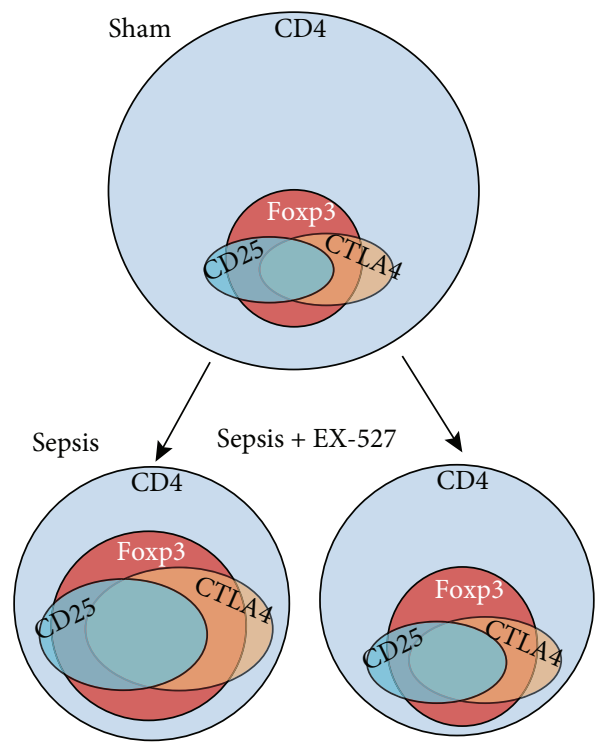

(e)

FIgURE 3: The frequency of CD4+Foxp3 $+\mathrm{T}_{\text {Reg }}$ cells reversibly increases in sepsis with SIRT1 inhibition. Cumulative results of CD4+Foxp3+ $\mathrm{T}_{\text {Reg }}$ cells presented as (a) frequency of CD4 (\%) and (b) absolute cell count. Cumulative results of CD4+Foxp3+CTLA4+ $\mathrm{T}_{\text {Reg }}$ cells presented as (c) frequency of CD4 (\%) and (d) absolute cell count. (e) Representative figure of the ratio changes in population size of CD4+ T cells and $\mathrm{CD} 4+\mathrm{T}_{\mathrm{Reg}}$ subpopulation. Markers are not representative of surface versus intracellular location. Data are representative of three independent analyses with a total of 5 mice in each group. Data are expressed as mean \pm SEM. $n=15$ mice/group. ${ }^{*} p<0.05$. 
$\mathrm{CD} 11 \mathrm{c}+$

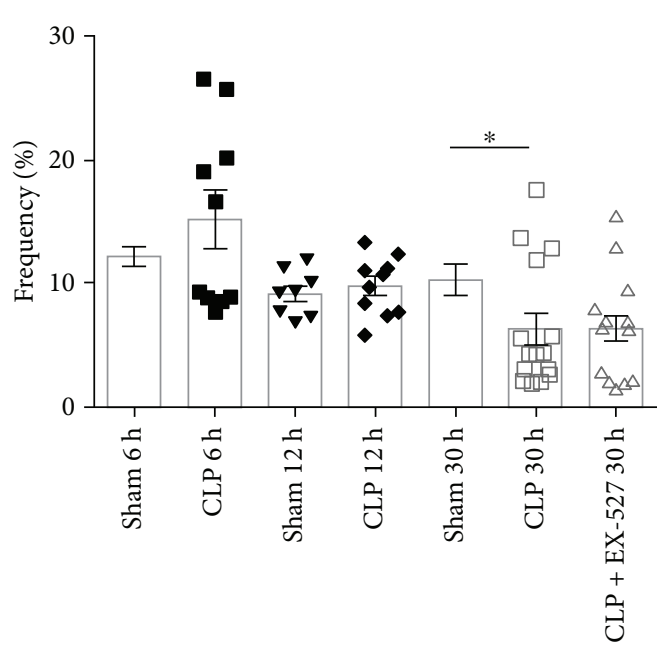

(a)

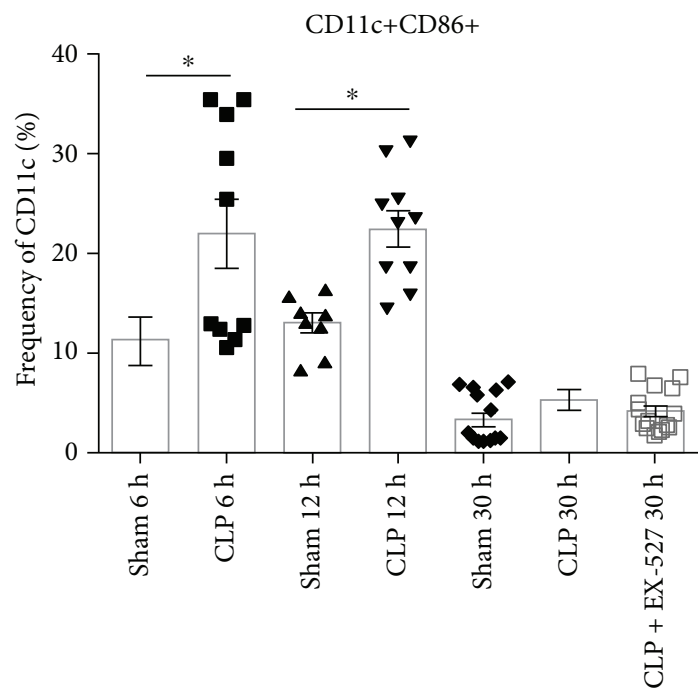

(c)
CD11+CD80+

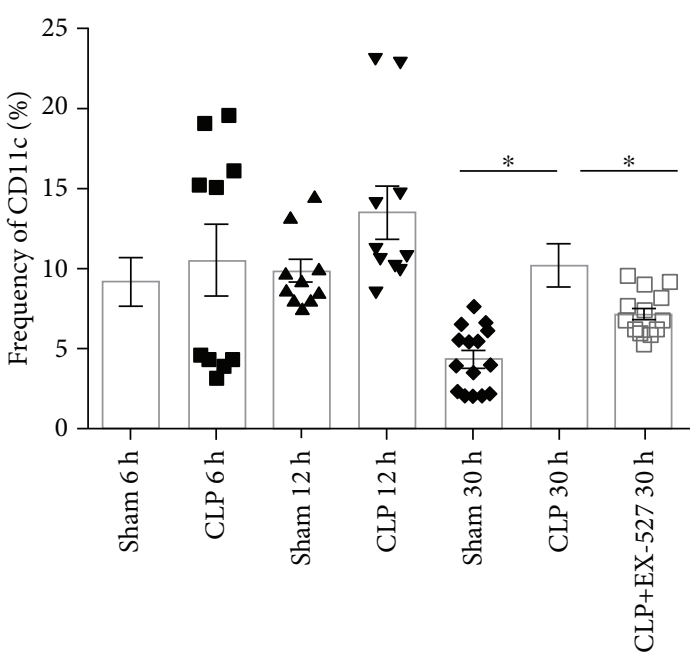

(b)

$\mathrm{CD} 11 \mathrm{c}+\mathrm{TNF} \alpha+$

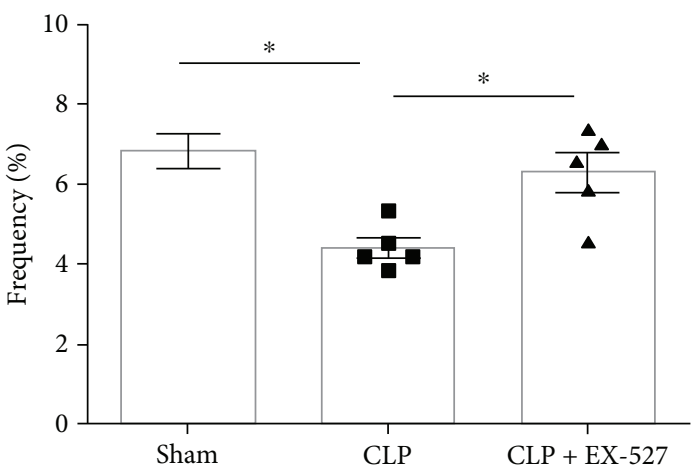

(d)

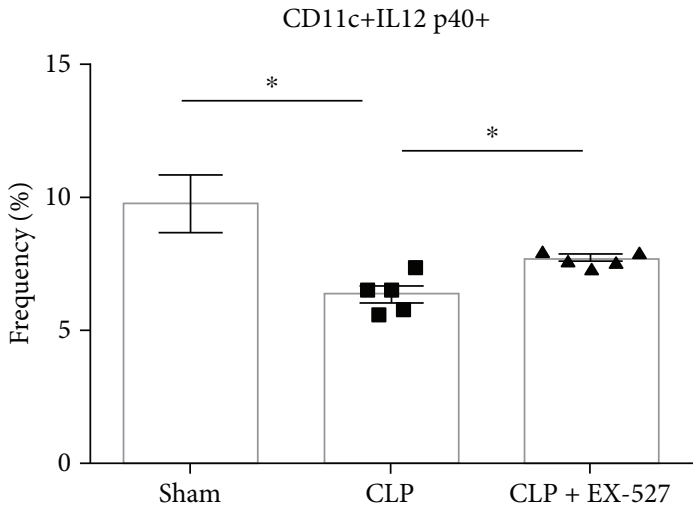

(e)

FIGURE 4: Effects of sepsis and SIRT1 inhibition on CD11c+ DC costimulatory markers. (a) Cumulative results of CD11c+ DCs presented as frequency of total splenocytes. (b, c) Cumulative data of CD11c+CD80+ DCs (b) and CD11c+CD86+ DCs (c) presented as frequency of CD11c. (d, e) Cumulative results of CD11c+ DC production of proinflammatory TNF $\alpha$ (d) and IL12 p40 (e) cytokines presented as frequency of CD11c. $(\mathrm{a}-\mathrm{c})$ Data are representative of two independent analyses with a total of 5 mice in each group. (d, e) Data are a single preliminary analysis with a total of 5 mice in each group. Data are expressed as mean \pm SEM. ${ }^{*} p<0.05$. 
cell homeostasis. However, as with $\mathrm{T}$ cells, we were unable to track expression of SIRT1 protein in dendritic cells by flow cytometry.

3.5. SIRT1 Inhibition Repolarizes the CD11c+ DC Tolerogenic and Activator Axis. To further define functional changes in $\mathrm{CD} 11 \mathrm{c}+\mathrm{DCs}$ that might influence $\mathrm{T}$ cell programming, pro- and anti-inflammatory cytokines were measured in splenic DCs. TNF $\alpha$ and IL12 p40 productions were measured to determine DC proinflammatory or activator responses, and IL10 and TGF $\beta$ were measured to determine DC antiinflammatory or tolerogenic responses. Figures 4(d) and 4(e) shows that both TNF $\alpha$ and IL12 p40 proinflammatory cytokines significantly decrease in CLP mice during sepsis tolerance $(30 \mathrm{~h})$ compared to sham $(p=0.0013$ and $p=$ 0.015 , resp.). SIRT1 inhibition increases TNF $\alpha$ and IL12 proinflammatory cytokine production in CD11c+ DCs to a level similar to sham (CLP versus CLP + EX-527; $p=0.0093$ and $p=0.0034$, resp.). Levels of IL10 and TGF $\beta$ in CD11c+ DCs at this time point were negligible (data not shown). Taken together, these data are compatible with the known function of SIRT1-dependent control of tolerogenic CD11c+ DC cell regulator of SIRT1-dependent adaptive immune polarity in the spleen of septic mice. These findings are consistent with our previous discovery that SIRT1 shifts innate immune monocytes from the tolerant phenotype to the activator phenotype during sepsis [5] and that the SIRT1 checkpoint may broadly influence reprogramming of innate and adaptive immunity reprograming during life-threatening sepsis.

\section{Discussion}

This study supports concordant control of innate and adaptive immunity axes during sepsis. The evidence supporting for this broad unifying pathophysiology concept includes that (1) $\mathrm{NAD}^{+}$-dependent and metabolic sensor SIRT1, as evidenced by the fact that a selective inhibitor EX-527 coordinates innate and adaptive immunity in septic mice, reprograms splenic CD11c+ DC subpopulation frequency from a tolerogenic to activator phenotype with increased expression of proimmune IL12 p40 and TNF $\alpha$; (2) treatment increases the proportion of IFN $\gamma$ effector CD4+ T cell subpopulations and decreases the frequency of CD4+Foxp3+ $\mathrm{T}_{\text {Reg }}$ CTLA4+ repressor cell proportions and decreases the frequency of $\mathrm{CD} 4+\mathrm{T}_{\mathrm{Reg}}$ cell expression of immune repressor cytokines TGF $\beta$ and IL10; (3) treatment reverses antigen-receptor immune tolerance among all splenocytes, as evidenced by increased interferon $\gamma$ immune expression; (4) and effects of a single dose of SIRT1-selective inhibitor EX-527 administered $24 \mathrm{~h}$ post-CLP persist for at least for $48 \mathrm{~h}$ in the CD4+ T population (Supplemental Figure S1/2).

Sepsis broadly dysregulates immune and organ cells and organism metabolism. Others [55-57] and we [4, 5, 9, 31] have shown that nuclear SIRT1, SIRT2, SIRT6, and mitochondrial SIRT3 drive immunometabolic reprogramming mechanistically by deacetylating key immune transcription factors, histone structural mediator regulatory factors, and methylating DNA [58]. SIRT1, lying proximal in immunometabolic signaling, deacetylates and inactivates NF- $\kappa \mathrm{B}$ p65 proimmune transcription factor function and supports a shift to supporting NF- $\kappa$ B RelB immune repressor functions by chromatin structural modifications [59]. SIRT1, SIRT2, SIRT6, SIRT3, and NF- $\kappa$ B, among other transcription and histone modifiers, ubiquitously control innate immune neutrophils, monocytes, and dendritic cells, as well as adaptive immunity CD4+CD8 T cells [30, 57, 60-63].

SIRT1, SIRT6, and SIRT3 are key redox sensors that inform glucose metabolism for use in effector immune anabolic signaling and its transition to repressed glucose use in increased activation of the lipolysis-fueled mitochondrial catabolism axis of resistance and tolerance [64, 65]. Glucose fueling directs proinflammatory responses and immune anabolic resistance mechanisms of both innate and adaptive immune cells [65-68]. In contrast, anti-inflammatory responses or immune tolerance, which is also marked by immune repressor $T_{\text {Reg }}$ cells, mostly use fatty acids for oxidative phosphorylation [31]. The importance for this study is that SIRT1 lies proximal to expression and functions of both nuclear SIRT6 and mitochondrial SIRT3 [65, 69-71] which form a key homeostasis regulatory node. This node and its downstream connections help coordinate anabolic and catabolic energy delivery to both immune and organ cells under stress. Inhibiting SIRT1 in septic mice increases glucose oxidation in splenocytes, while enhancing the innate immune response $[4,9,32]$. The importance for interpreting this study is that innate immune reprogramming of monocytes in septic mice occurs at the same time which dendritic cells and $\mathrm{T}$ cells reprogrammed from tolerance to resistance pathways in this study, as previously published [9]. Since SIRT1 lies proximal to altered immunometabolic programming, what lies proximal to the SIRT axis? Redox control of SIRT1 cysteine thiols also informs its deacetylase activity in cells under stress, which directs lipolysis versus lipogenesis [72-74]. We recently found that the direct and reversible oxidative state of cysteine thiol 144 on SIRT6 informs its glucose homeostat property [30], a critical pivot for substrate switching between glucose driven resistance and fatty acid driven tolerance in septic mice. Thus, mounting data suggest that redox oxidation and reduction switching drive fuel selection among immune cells and may occupy a more fundamental site for inflammation and immune regulation in sepsis. Supporting this are our recent findings that mitochondrial SIRT4 counters the redox regulation of SIRT1, SIRT6, and SIRT3 by increasing glycolysis and its support of glucose oxidation [75].

This study has important limitations. One is that we were unable to pin point in which immune cell(s) SIRT1 might be primarily directing immune axis polarity shifting among the cell types investigated in this study, since our antibodies were unable to detect SIRT1 in Western blot of histochemical analyses. The most clear example of a potential site from in vivo study was the recent report using pharmacologic and genetic deletion and addition analyses in C57BL6 mice and endotoxin treatment (not sepsis), which clearly linked SIRT1 in CD11c dendritic cells to reprogram the axis between $\mathrm{CD} 4+\mathrm{Th} 1$ cells and $\mathrm{CD} 4+\mathrm{T}_{\text {Reg }}$ repressor cells [36]; these results parallel what may be occurring in this 


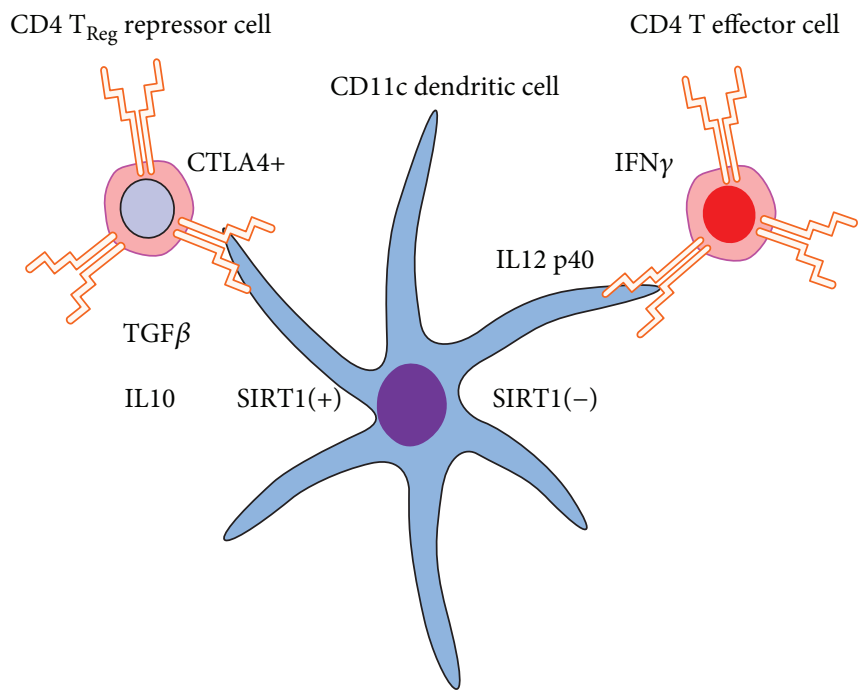

FIGURE 5: Effects of SIRT1 inhibition on dendritic and CD4 effector and repressor immunity during sepsis. SIRT1 increases during the immunometabolic stage of sepsis coordinates innate tolerogenic dendritic cell and CD4 T cell repressor and immune inhibitory IL10 and TGF $\beta$ cytokines. SIRT1 therapeutic inhibition reverses both the innate to adaptive immune CD4 effector cell interactions and effector immune cytokines (e.g., IL12 p40 and interferon $\gamma$ levels). It is unclear in which cell or cell nuclear SIRT1 is acting to guard resistance and tolerant sepsis inflammatory responses.

sepsis in this study, and mechanistically this path requires deacetylation of NF- $\kappa$ B p64 [5]. However, SIRT1 and other nuclear SIRTs can broadly act on innate and adaptive cells in a cell autonomous paths [76]. The second limitation is that genetic analysis is not yet possible in studying tolerance kinetically and investigations like this one must rely on drug targeting and the possibility of off target effects. Although EX-527 is a highly selective SIRT1 inhibitor at the dose used in this study [41], it may have unrecognized off target effects. Moreover, we also did not define how long the effects on SIRT1 on reversing global immunity might last, an important issue in translating this concept to human sepsis. The third limitation relates to our recent discovery that SIRT2 and not SIRT1 regulates the immune homeostasis node in obese septic mice [55], lending support to the concept that redox regulation informs the SIRT family for homeostasis regulation depending on the cell type or organism energy phenotype.

In conclusion, this study shows for the first time in a lethal model of sepsis in mice that a regulatory node controlled by a selective SIRT1 inhibitor known to improved sepsis survival [9] coordinates innate and adaptive immune cell polarity. Figure 5 schematically demonstrates this discovery. A plausible common mechanistic explanation for SIRT1 bridging of both innate and adaptive immunity is its known effects of controlling immunometabolism reprogramming by epigenetically switching immune resistance mechanisms to immune tolerance mechanisms. This broad-based homeostasis axis is likely multimechanistic and not explained by targeted mechanistic studies so popular with reductionist biomedical investigations. However, it may open the way to better understand sepsis resolution and it informs broad-based immune targeting as potential sepsis treatment.

\author{
Abbreviations \\ EX-527: Selective SIRT1 inhibitor \\ CLP: Cecal ligation and puncture \\ Foxp3: Transcription factor \\ SIRT: Sirtuin \\ $\mathrm{T}_{\text {Reg }}$ : Regulatory $\mathrm{T}$ cell.
}

\section{Data Availability}

The data used to support the findings of this study are available from the corresponding author upon request.

\section{Conflicts of Interest}

The authors have no conflicts to report.

\section{Authors' Contributions}

Charles E. McCall, Ayana N. Martin, Martha AlexanderMiller, and Vidula Vachharajani designed the study. Martha Alexander-Miller guided the flow cytometry experiments and its interpretations. Barbara K. Yoza managed the overall data presentation, Ayana N. Martin conducted the experiments, and Ayana N. Martin and Charles E. McCall wrote the manuscript.

\section{Acknowledgments}

The authors thank Richard Hotchkiss and his laboratory for help on the Mouse IFN $\gamma$ ELISPOT technique, presentation, and analysis. This work was supported by the National Institutes of Health Grants RO1AI079144, R01AI065791 and S1, and R01GM102497 to Charles E. McCall and GMR01099807 to Vidula Vachharajani. 


\section{Supplementary Materials}

Supplementary 1. Figure 1: representative flow cytometry data of T cell subpopulations. Splenocytes from sham, sepsis (CLP), and septic mice treated with EX-527 (CLP + EX-527) were analyzed by FACS. Representative FACS data of CD8+ versus CD4+ T cells (A) and Foxp3+ versus CD4+ T cells (B). Gated cells are CD4+Foxp3+. Representative FACS data of CTLA4+ versus Foxp3+ T cells (C). Cells are gated on $\mathrm{CD} 4+$. Data are representative of three independent analyses; $n=15$ mice/group.

Supplementary 2. Figure 2: the decrease in CD4+Foxp $3+\mathrm{T}_{\mathrm{Reg}}$ cells is maintained with SIRT1 inhibition at $48 \mathrm{~h}$ and the effect of SIRT1 inhibition on CD4+ reprogramming. FACS analysis CD4+ T cells (A) and CD4+Foxp3+ cells (B) at 12 ( $n=5 \mathrm{mice} /$ group), 30 ( $n=15 \mathrm{mice} /$ group $)$, or $48 \mathrm{~h}(n=5$ mice/group) from sham, sepsis (CLP), and septic mice treated with EX-527 (CLP + EX-527). Data expressed as mean \pm SEM. (C) Graphic representation of SIRT1 reprogramming CD4+ cells during sepsis.

\section{References}

[1] R. Chovatiya and R. Medzhitov, "Stress, inflammation, and defense of homeostasis," Molecular Cell, vol. 54, no. 2, pp. 281-288, 2014.

[2] R. Medzhitov, D. S. Schneider, and M. P. Soares, "Disease tolerance as a defense strategy," Science, vol. 335, no. 6071, pp. 936-941, 2012.

[3] R. Medzhitov, "Septic shock: on the importance of being tolerant," Immunity, vol. 39, no. 5, pp. 799-800, 2013.

[4] T. F. Liu, V. T. Vachharajani, B. K. Yoza, and C. E. McCall, "NAD ${ }^{+}$-dependent sirtuin 1 and 6 proteins coordinate a switch from glucose to fatty acid oxidation during the acute inflammatory response," Journal of Biological Chemistry, vol. 287, no. 31, pp. 25758-25769, 2012.

[5] T. F. Liu, B. K. Yoza, M. El Gazzar, V. T. Vachharajani, and C. E. McCall, "NAD"-dependent SIRT1 deacetylase participates in epigenetic reprogramming during endotoxin tolerance," Journal of Biological Chemistry, vol. 286, no. 11, pp. 9856-9864, 2011.

[6] B. K. Yoza and C. E. McCall, "Facultative heterochromatin formation at the IL-1 beta promoter in LPS tolerance and sepsis," Cytokine, vol. 53, no. 2, pp. 145-152, 2011.

[7] T. F. Liu, C. M. Brown, M. El Gazzar et al., "Fueling the flame: bioenergy couples metabolism and inflammation," Journal of Leukocyte Biology, vol. 92, no. 3, pp. 499-507, 2012.

[8] S. L. Foster and R. Medzhitov, "Gene-specific control of the TLR-induced inflammatory response," Clinical Immunology, vol. 130, no. 1, pp. 7-15, 2009.

[9] V. T. Vachharajani, T. Liu, C. M. Brown et al., "SIRT1 inhibition during the hypoinflammatory phenotype of sepsis enhances immunity and improves outcome," Journal of Leukocyte Biology, vol. 96, no. 5, pp. 785-796, 2014.

[10] S. C. Cheng, B. P. Scicluna, R. J. Arts et al., "Broad defects in the energy metabolism of leukocytes underlie immunoparalysis in sepsis," Nature Immunology, vol. 17, no. 4, pp. 406413, 2016.

[11] N. Patsoukis, K. Bardhan, P. Chatterjee et al., "PD-1 alters T-cell metabolic reprogramming by inhibiting glycolysis and promoting lipolysis and fatty acid oxidation," Nature Communications, vol. 6, no. 1, p. 6692, 2015.

[12] A. D. Wells, "New insights into the molecular basis of T cell anergy: anergy factors, avoidance sensors, and epigenetic imprinting," The Journal of Immunology, vol. 182, no. 12, pp. 7331-7341, 2009.

[13] E. J. Wherry and M. Kurachi, "Molecular and cellular insights into T cell exhaustion," Nature Reviews Immunology, vol. 15, no. 8, pp. 486-499, 2015.

[14] D. R. Sen, J. Kaminski, R. A. Barnitz et al., "The epigenetic landscape of T cell exhaustion," Science, vol. 354, no. 6316, pp. 1165-1169, 2016.

[15] E. L. Pearce, M. C. Poffenberger, C. H. Chang, and R. G. Jones, "Fueling immunity: insights into metabolism and lymphocyte function," Science, vol. 342, no. 6155, article 1242454, 2013.

[16] J. Blagih and R. G. Jones, "Polarizing macrophages through reprogramming of glucose metabolism," Cell Metabolism, vol. 15, no. 6, pp. 793-795, 2012.

[17] C. M. Krawczyk, T. Holowka, J. Sun et al., “Toll-like receptorinduced changes in glycolytic metabolism regulate dendritic cell activation," Blood, vol. 115, no. 23, pp. 4742-4749, 2010.

[18] A. El-Osta, D. Brasacchio, D. Yao et al., "Transient high glucose causes persistent epigenetic changes and altered gene expression during subsequent normoglycemia," Journal of Experimental Medicine, vol. 205, no. 11, p. 2683, 2008.

[19] R. S. Hotchkiss, G. Monneret, and D. Payen, "Sepsis-induced immunosuppression: from cellular dysfunctions to immunotherapy," Nature Reviews Immunology, vol. 13, no. 12, pp. 862-874, 2013.

[20] W. K. E. Ip, N. Hoshi, D. S. Shouval, S. Snapper, and R. Medzhitov, "Anti-inflammatory effect of IL-10 mediated by metabolic reprogramming of macrophages," Science, vol. 356, no. 6337, pp. 513-519, 2017.

[21] Y. Xiong, F. Qiu, W. Piao, C. Song, L. M. Wahl, and A. E. Medvedev, "Endotoxin tolerance impairs IL-1 receptorassociated kinase (IRAK) 4 and TGF- $\beta$-activated kinase 1 activation, K63-linked polyubiquitination and assembly of IRAK1, TNF receptor-associated factor 6 , and $\mathrm{I} \kappa \mathrm{B}$ kinase $\gamma$ and increases A20 expression," Journal of Biological Chemistry, vol. 286, no. 10, pp. 7905-7916, 2011.

[22] J. S. Boomer, K. To, K. C. Chang et al., "Immunosuppression in patients who die of sepsis and multiple organ failure," JAMA, vol. 306, no. 23, pp. 2594-2605, 2011.

[23] A. H. Walton, J. T. Muenzer, D. Rasche et al., "Reactivation of multiple viruses in patients with sepsis," PLoS One, vol. 9, no. 6, article e98819, 2014.

[24] I. N. Shalova, J. Y. Lim, M. Chittezhath et al., "Human monocytes undergo functional re-programming during sepsis mediated by hypoxia-inducible factor- $1 \alpha$," Immunity, vol. 42 , no. 3, pp. 484-498, 2015.

[25] N. Poulose and R. Raju, "Sirtuin regulation in aging and injury," Biochimica et Biophysica Acta (BBA) - Molecular Basis of Disease, vol. 1852, no. 11, pp. 2442-2455, 2015.

[26] T. F. Liu and C. E. McCall, "Deacetylation by SIRT1 reprograms inflammation and cancer," Genes \& Cancer, vol. 4, no. 3-4, pp. 135-147, 2013.

[27] A. Chalkiadaki and L. Guarente, "Metabolic signals regulate SIRT1 expression," EMBO Reports, vol. 12, no. 10, pp. 985986, 2011.

[28] T. T. Schug and X. Li, "Sirtuin 1 in lipid metabolism and obesity," Annals of Medicine, vol. 43, no. 3, pp. 198-211, 2011. 
[29] L. Guarente, "Sirtuins in aging and disease," Cold Spring Harbor Symposia on Quantitative Biology, vol. 72, no. 1, pp. 483-488, 2007.

[30] D. Long, H. Wu, A. W. Tsang et al., "The oxidative state of cysteine thiol 144 regulates the SIRT6 glucose homeostat," Scientific Reports, vol. 7, no. 1, article 11005, 2017.

[31] V. T. Vachharajani, T. Liu, X. Wang, J. J. Hoth, B. K. Yoza, and C. E. McCall, "Sirtuins link inflammation and metabolism," Journal of Immunology Research, vol. 2016, Article ID 8167273, 10 pages, 2016.

[32] T. F. Liu, V. Vachharajani, P. Millet, M. S. Bharadwaj, A. J. Molina, and C. E. McCall, "Sequential actions of SIRT1-RELB-SIRT3 coordinate nuclear-mitochondrial communication during immunometabolic adaptation to acute inflammation and sepsis," Journal of Biological Chemistry, vol. 290, no. 1, pp. 396-408, 2015.

[33] M. P. Gillum, M. E. Kotas, D. M. Erion et al., "SirT1 regulates adipose tissue inflammation," Diabetes, vol. 60, no. 12, pp. 3235-3245, 2011.

[34] T. Yoshizaki, S. Schenk, T. Imamura et al., "SIRT1 inhibits inflammatory pathways in macrophages and modulates insulin sensitivity," American Journal of Physiology Endocrinology and Metabolism, vol. 298, no. 3, pp. E419E428, 2010.

[35] B. Kelly and L. A. O'Neill, "Metabolic reprogramming in macrophages and dendritic cells in innate immunity," Cell Research, vol. 25, no. 7, pp. 771-784, 2015.

[36] G. Liu, Y. Bi, L. Xue et al., "Dendritic cell SIRT1-HIF1 $\alpha$ axis programs the differentiation of $\mathrm{CD}^{+} \mathrm{T}$ cells through IL-12 and TGF- $\beta 1$," Proceedings of the National Academy of Sciences of the United States of America, vol. 112, no. 9, pp. E957E965, 2015.

[37] D. Lasiglie, S. Boero, I. Bauer et al., "Sirt 6 regulates dendritic cell differentiation, maturation, and function," Aging, vol. 8, no. 1, pp. 34-47, 2016.

[38] A. B. Owczarczyk, M. A. Schaller, M. Reed, A. J. Rasky, D. B. Lombard, and N. W. Lukacs, "Sirtuin 1 regulates dendritic cell activation and autophagy during respiratory syncytial virusinduced immune responses," The Journal of Immunology, vol. 195, no. 4, pp. 1637-1646, 2015.

[39] J. F. Codocedo, C. Allard, J. A. Godoy, L. Varela-Nallar, and N. C. Inestrosa, "SIRT1 regulates dendritic development in hippocampal neurons," PLoS One, vol. 7, no. 10, article e47073, 2012.

[40] M. Y. Jeng, P. A. Hull, M. Fei et al., "Metabolic reprogramming of human $\mathrm{CD}^{+}$memory T cells through loss of SIRT1," The Journal of Experimental Medicine, vol. 215, no. 1, pp. 51-62, 2018.

[41] M. Gertz, F. Fischer, G. T. Nguyen et al., "Ex-527 inhibits Sirtuins by exploiting their unique $\mathrm{NAD}^{+}$-dependent deacetylation mechanism," Proceedings of the National Academy of Sciences of the United States of America, vol. 110, no. 30, pp. E2772-E2781, 2013.

[42] A. D. Napper, J. Hixon, T. McDonagh et al., "Discovery of indoles as potent and selective inhibitors of the deacetylase SIRT1," Journal of Medicinal Chemistry, vol. 48, no. 25, pp. 8045-8054, 2005.

[43] H. Zeng and H. Chi, "mTOR signaling in the differentiation and function of regulatory and effector $\mathrm{T}$ cells," Current Opinion in Immunology, vol. 46, pp. 103111, 2017.
[44] R. S. Hotchkiss, C. M. Coopersmith, J. E. McDunn, and T. A. Ferguson, "The sepsis seesaw: tilting toward immunosuppression," Nature Medicine, vol. 15, no. 5, pp. 496-497, 2009.

[45] F. Venet, C. S. Chung, H. Kherouf et al., "Increased circulating regulatory $\mathrm{T}$ cells $\left(\mathrm{CD} 4^{+} \mathrm{CD} 25^{+} \mathrm{CD} 127^{-}\right)$contribute to lymphocyte anergy in septic shock patients," Intensive Care Medicine, vol. 35, no. 4, pp. 678-686, 2009.

[46] F. Venet, A. Pachot, A. L. Debard et al., "Increased percentage of $\mathrm{CD} 4+\mathrm{CD} 25+$ regulatory T cells during septic shock is due to the decrease of CD4+CD25- lymphocytes," Critical Care Medicine, vol. 32, no. 11, pp. 2329-2331, 2004.

[47] R. J. DiPaolo, C. Brinster, T. S. Davidson, J. Andersson, D. Glass, and E. M. Shevach, "Autoantigen-specific TGF $\beta$-induced Foxp $3^{+}$regulatory $\mathrm{T}$ cells prevent autoimmunity by inhibiting dendritic cells from activating autoreactive T cells," The Journal of Immunology, vol. 179, no. 7, pp. 4685-4693, 2007.

[48] K. A. Frauwirth and C. B. Thompson, "Activation and inhibition of lymphocytes by costimulation," The Journal of Clinical Investigation, vol. 109, no. 3, pp. 295-299, 2002.

[49] M. Wysocka, L. J. Montaner, and C. L. Karp, "Flt3 ligand treatment reverses endotoxin tolerance-related immunoparalysis," The Journal of Immunology, vol. 174, no. 11, pp. 7398-7402, 2005.

[50] M. Wysocka, S. Robertson, H. Riemann et al., "IL-12 suppression during experimental endotoxin tolerance: dendritic cell loss and macrophage hyporesponsiveness," The Journal of Immunology, vol. 166, no. 12, pp. 7504-7513, 2001.

[51] A. Nolan, H. Kobayashi, B. Naveed et al., "Differential role for CD80 and CD86 in the regulation of the innate immune response in murine polymicrobial sepsis," PLoS One, vol. 4, no. 8 , article e6600, 2009.

[52] D. M. Sansom, C. N. Manzotti, and Y. Zheng, "What's the difference between CD80 and CD86?," Trends in Immunology, vol. 24, no. 6, pp. 314-319, 2003.

[53] P. A. van der Merwe, D. L. Bodian, S. Daenke, P. Linsley, and S. J. Davis, "CD80 (B7-1) binds both CD28 and CTLA-4 with a low affinity and very fast kinetics," The Journal of Experimental Medicine, vol. 185, no. 3, pp. 393-404, 1997.

[54] R. S. Hotchkiss, K. W. Tinsley, and I. E. Karl, "Role of apoptotic cell death in sepsis," Scandinavian Journal of Infectious Diseases, vol. 35, no. 9, pp. 585-592, 2003.

[55] X. Wang, N. L. Buechler, A. Martin et al., "Sirtuin-2 regulates sepsis inflammation in ob/ob mice," PLoS One, vol. 11, no. 8, article e0160431, 2016.

[56] T. Zhang and W. L. Kraus, "SIRT1-dependent regulation of chromatin and transcription: linking $\mathrm{NAD}^{+}$metabolism and signaling to the control of cellular functions," Biochimica et Biophysica Acta (BBA) - Proteins and Proteomics, vol. 1804, no. 8, pp. 1666-1675, 2010.

[57] F. Yeung, J. E. Hoberg, C. S. Ramsey et al., "Modulation of NF- $\kappa \mathrm{B}$-dependent transcription and cell survival by the SIRT1 deacetylase," The EMBO Journal, vol. 23, no. 12, pp. 23692380, 2004.

[58] N. Preyat and O. Leo, "Sirtuin deacylases: a molecular link between metabolism and immunity," Journal of Leukocyte Biology, vol. 93, no. 5, pp. 669-680, 2013.

[59] B. K. Yoza, J. Y. Hu, S. L. Cousart, L. M. Forrest, and C. E. McCall, "Induction of RelB participates in endotoxin tolerance," The Journal of Immunology, vol. 177, no. 6, pp. 4080-4085, 2006.

[60] P. A. Baeuerle and D. Baltimore, "NF- $\kappa$ B: ten years after," Cell, vol. 87, no. 1, pp. 13-20, 1996. 
[61] A. Salminen, A. Kauppinen, T. Suuronen, and K. Kaarniranta, "SIRT1 longevity factor suppresses NF- $\kappa \mathrm{B}$-driven immune responses: regulation of aging via NF- $\kappa \mathrm{B}$ acetylation?," BioEssays, vol. 30, no. 10, pp. 939-942, 2008.

[62] X. Chen, M. El Gazzar, B. K. Yoza, and C. E. McCall, “The NF- $\kappa$ B factor RelB and histone $\mathrm{H} 3$ lysine methyltransferase G9a directly interact to generate epigenetic silencing in endotoxin tolerance," Journal of Biological Chemistry, vol. 284, no. 41, pp. 27857-27865, 2009.

[63] C. E. McCall and B. K. Yoza, "Gene silencing in severe systemic inflammation," American Journal of Respiratory and Critical Care Medicine, vol. 175, no. 8, pp. 763-767, 2007.

[64] N. J. Mac Iver and J. C. Rathmell, "Editorial overview: metabolism of T cells: integrating nutrients, signals, and cell fate," Current Opinion in Immunology, vol. 46, pp. viii-vixi, 2017.

[65] B. A. Olenchock, J. C. Rathmell, and M. G. Vander Heiden, "Biochemical underpinnings of immune cell metabolic phenotypes," Immunity, vol. 46, no. 5, pp. 703-713, 2017.

[66] P. J. Siska and J. C. Rathmell, "Metabolic signaling drives IFN$\gamma$," Cell Metabolism, vol. 24, no. 5, pp. 651-652, 2016.

[67] R. M. Loftus and D. K. Finlay, "Immunometabolism: cellular metabolism turns immune regulator," Journal of Biological Chemistry, vol. 291, no. 1, pp. 1-10, 2016.

[68] C. S. Palmer, M. Ostrowski, B. Balderson, N. Christian, and S. M. Crowe, "Glucose metabolism regulates T cell activation, differentiation, and functions," Frontiers in Immunology, vol. 6, p. 1, 2015.

[69] I. A. Bettencourt and J. D. Powell, "Targeting metabolism as a novel therapeutic approach to autoimmunity, inflammation, and transplantation," Journal of Immunology, vol. 198, no. 3, pp. 999-1005, 2017.

[70] L. A. O'Neill and E. J. Pearce, "Immunometabolism governs dendritic cell and macrophage function," Journal of Experimental Medicine, vol. 213, no. 1, pp. 15-23, 2016.

[71] G. D. Norata, G. Caligiuri, T. Chavakis et al., "The cellular and molecular basis of translational immunometabolism," Immunity, vol. 43, no. 3, pp. 421-434, 2015.

[72] J. L. Feldman, K. E. Dittenhafer-Reed, N. Kudo et al., "Kinetic and structural basis for acyl-group selectivity and $\mathrm{NAD}^{+}$ dependence in sirtuin-catalyzed deacylation," Biochemistry, vol. 54, no. 19, pp. 3037-3050, 2015.

[73] S. Caito, S. Rajendrasozhan, S. Cook et al., "SIRT1 is a redoxsensitive deacetylase that is post-translationally modified by oxidants and carbonyl stress," The FASEB Journal, vol. 24, no. 9, pp. 3145-3159, 2010.

[74] M. D. Kornberg, N. Sen, M. R. Hara et al., "GAPDH mediates nitrosylation of nuclear proteins," Nature Cell Biology, vol. 12, no. 11, pp. 1094-1100, 2010.

[75] J. Tao, J. Zhang, Y. Ling, C. E. McCall, and T. F. Liu, "Mitochondrial Sirtuin 4 resolves immune tolerance in monocytes by rebalancing glycolysis and glucose oxidation homeostasis," Frontiers in Immunology, vol. 9, p. 419, 2018.

[76] D. Toiber, C. Sebastian, and R. Mostoslavsky, "Characterization of nuclear sirtuins: molecular mechanisms and physiological relevance," Handbook of Experimental Pharmacology, vol. 206, pp. 189-224, 2011. 


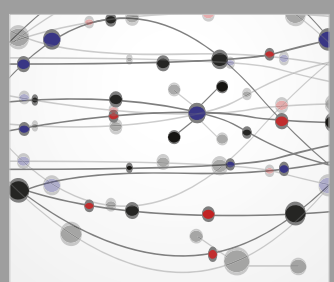

The Scientific World Journal
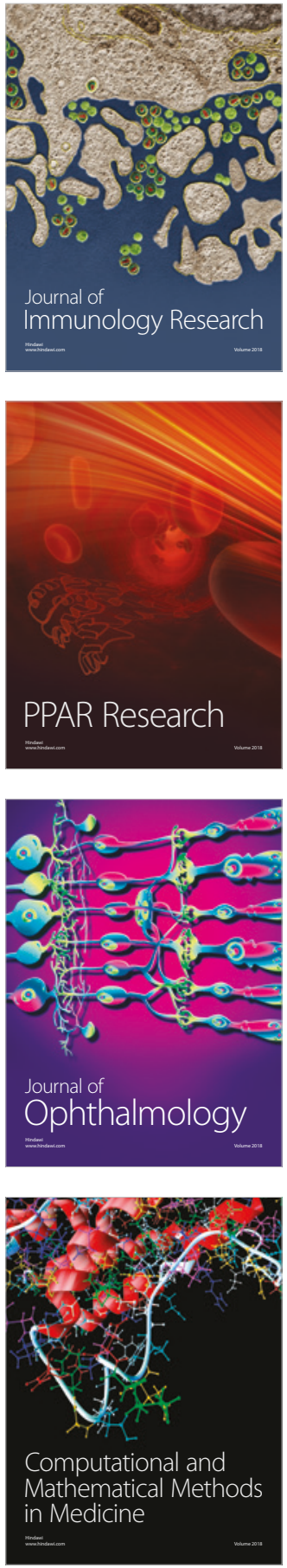

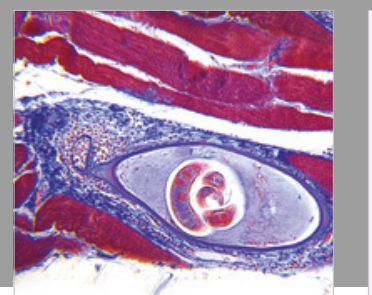

Gastroenterology Research and Practice

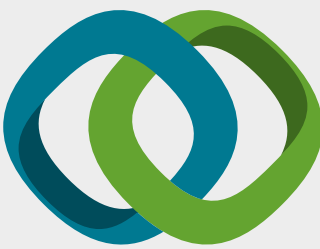

\section{Hindawi}

Submit your manuscripts at

www.hindawi.com
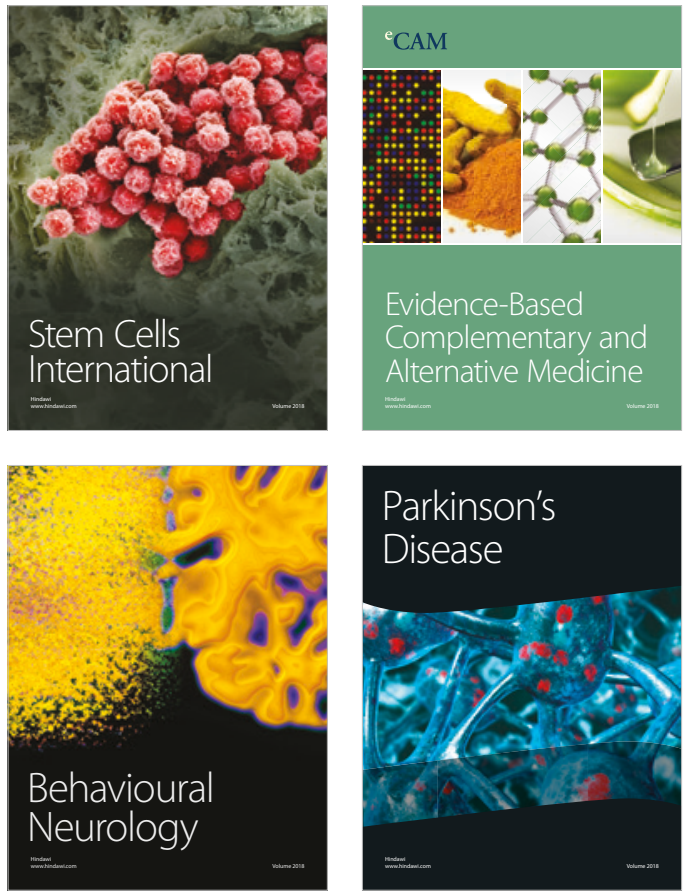

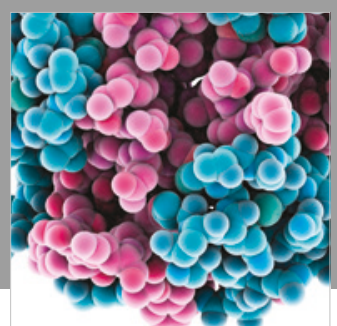

ournal of

Diabetes Research

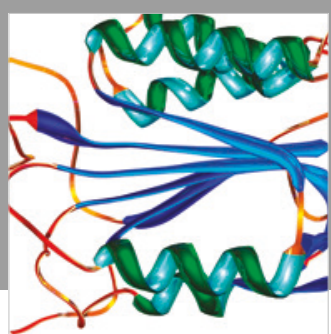

Disease Markers
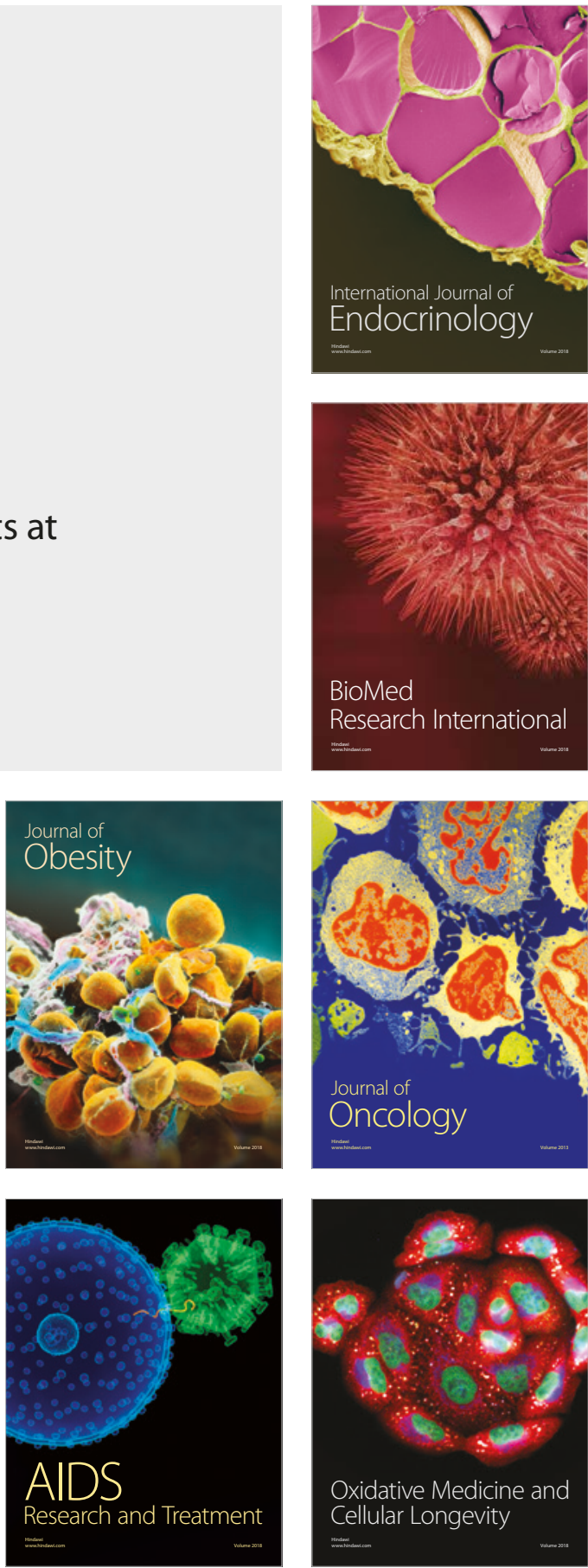